\title{
The Potential Applications of a Silica Polymer to Absorb Carbon Dioxide
}

\begin{abstract}
Keywords: Silica polymer; Cardon dioxide
Abstract

Due to the role of $\mathrm{CO}_{2}$ emissions in causing anthropogenic climate change and the relevance and prospects for reducing emissions, monitoring carbon dioxide $\left(\mathrm{CO}_{2}\right)$ emissions to the atmosphere from fossi fuel combustion, non-energy usage of fossil fuels, and other industrial activities is necessary. Experts have warned that global pollution will reach dangerous levels, and the United Nations has warned of the disastrous consequences of pollution if governments do not take action to cut carbon emissions. The goal of this research is to achieve zero emissions, which means that we do not add new emissions to the atmosphere. Emissions will continue, but this will be offset by the absorption of a similar amount from the atmosphere. In this study, we use thermal fusion technology to create a polymer that can absorb carbon dioxide gas from the atmosphere from a base of liquid sodium silicate with the addition of sodium microchloride i.e., liquid. The results showed a significant decrease in the carbon dioxide level by $53 \%$, which a pioneering step towards achieving zero emissions.
\end{abstract}

\section{Introduction}

Experts have warned that environmental pollution in the world will reach dangerous levels, while the United Nations has warned of the devastating effects of pollution if the countries of the world do not take decisions to reduce carbon emissions [1]. The Paris Climate Agreement urged signatory countries to reduce greenhouse gas emissions; In order to reduce the temperature of the Earth's atmosphere by 1.5 degrees Celsius. The agreement concluded in 2015 on the sidelines of the twenty-first climate summit in the French capital (Paris) stipulates the commitment of all 195 countries to combat the causes of climate change [2]. According to a recent study prepared by researchers from Duke University in the United States and published in the journal Nature Climate Change, the lives of approximately 153 million people could be saved, who may be at risk of premature death during this century, if governments speed up their measures to reduce dependence on fossil fuels. It means reducing harmful carbon dioxide emissions. The study is the first of its kind to estimate how many people could be saved from the risk of premature death due to greenhouse gas air pollution [3].

In fact, Plastic is a major source of carbon pollution but is often overlooked. Production in the United States reaches at least 232 million metric tons of greenhouse gases, according to a report by Bennington College and the nonprofit organization Beyond Plastics, plastic production is expected to emit another 55 million tons by 2025 if 42 planned plants are put into operation. Currently or under construction [4].

Much of the carbon pollution in plastics comes from the fracturing processes and the transfer of gases used in production. One of them is methane, a powerful greenhouse gas that heats the

\section{Environmental Studies}

\author{
Hesham Mohamed Abdal-Salam Yehia* and Said \\ Mahmoud Said
}

Department of Biotechnology, HST Company, Egypt

*Address for Correspondence

Hesham Mohamed Abdal-Salam Yehia, Department of Bio technology, HST Company, Egypt, E-mail: hyehia@hlogic group.com

Submission: 01 December, 2021

Accepted: 30 December, 2021

Published: 05 January, 2022

Copyright: (c) 2022 Hesham Mohamed Yehia AS, et al. This is an open access article distributed under the Creative Commons Attribution License, which permits unrestricted use, distribution, and reproduction in any medium, provided the original work is properly cited.

atmosphere 86 times more than the same amount of carbon dioxide over the course of 20 years [5]. The report says that leaks at wellheads and along pipelines create 36 million tons of carbon pollution. Other parts of natural gas, such as ethane, are used as feedstock, and fracking produces another 70 million tons $[5,6]$. Other plastic feedstocks such as coal and ammonia are produced 28 million additional tons. Burning plastic waste is responsible for 15 million tons of carbon pollution, and the report says that even so-called "chemical recycling", which typically uses high heat to melt plastic into component parts, could add another 18 million tons by 2025 [7].

Other sources of methane, over which humans have little influence, are also a source of concern. With extensive observations in the Arctic, Europe, and the tropics, as well as related modelling studies, an international consortium of researchers has been tracking methane emissions. The increase in methane emissions since 2007 appears to be related to increased biological emissions, especially in the tropics, according to the study. Rising temperatures and greater precipitation, among other things, have accelerated such activities, causing the spread of tropical wetlands [8]. Therefore, this research is a pioneering step towards developing an effective material that can absorb carbon dioxide from the air and thus contribute to reducing pollution without consuming additional energy.

\section{Research problem}

Carbon dioxide emissions cause climate changes at the level of environmental impact and air pollution, as they have contributed to the increase in the surface temperature of the Earth over the past 100 years. Carbon dioxide pollution is the primary culprit, the effects are very complex, and evidence shows, ocean water levels have increased, resulting in the loss of coastlines and coastal wetlands. Carbon dioxide also contributes to air pollution in its role in the greenhouse effect, and carbon dioxide traps radiation at ground level, which leads to the creation of an ozone layer at ground level. This layer of air prevents the earth from cooling at night. As the ocean warms, rising water temperatures harm the oceans' ability to absorb carbon dioxide. Over time, the effects of carbon dioxide are exacerbated. Last year, greenhouse gases in the atmosphere reached a new record, 
Citation: Hesham Mohamed Yehia AS, Mahmoud Said S. The Potential Applications of a Silica Polymer to Absorb Carbon Dioxide. J Environ Stud. 2021;7(1): 3 .

ISSN: $2471-4879$

exceeding the average planet between 2011-2020, and continuing into 2021, according to a Raftery et al (2017) report, as shown in Figure 1.

A large number of recent studies on future climate impacts have concentrated on the "RCP 8.5 " warming scenario. This highemissions scenario is sometimes referred to as "business as usual," implying that it will occur until society makes substantial steps to reduce greenhouse gas emissions.

\section{Research questions}

How can a polymer of silica absorb carbon dioxide?

To what degree can carbon be absorbed through a polymer of silica?

\section{Materials and Methods}

The polymer of silica used in this paper is a new method for absorbing carbon dioxide from the atmosphere that involves adding micro sodium chloride to a polymer of liquid sodium silicate in an environment completely isolated from the air and at a temperature of $30^{\circ} \mathrm{C}$ to form a polymer that can absorb carbon dioxide when exposed to the atmosphere again. Sodium silicate material is created using thermal fusion technology, which involves mixing sodium carbonate with silicon dioxide in a furnace heated to 1300 degrees Celsius to produce silica stone with molecular formula $\mathrm{Na}_{2} \mathrm{SiO}_{3}$. It is a viscous substance on neutral liquid sodium silicate, and then our polymerization process takes place to produce a polymer that can absorb carbon dioxide from the air. As a result, carbon contaminants are removed from the air and cleansed.

The second stage is to dissolve the carbon dioxide stored in the material in water, resulting in a dilute carbonic acid that reacts with the existing sodium atom to form sodium carbonate, which can be used commercially and has a wide range of applications, while a large portion of the sodium silicate remains. The issue that mankind faces is to discover practical and affordable scientific solutions to conserve the environment and limit carbon dioxide emissions into the air. We can transform what is accessible to what is achievable with this technology, which we are happy to provide. We also ensured that all components are ecologically safe and do not include volatile organic chemicals, as well as that they do not contain hazardous substances or materials containing radiation or charged parts. The recent conference on the environment in Glasgow, United Kingdom, lay forth a road map for governments and peoples to achieve sustainable development, including the passage of environmental legislation. As the world's greatest task is to eliminate 31 billion tons of pollutants that influence the climate each year, the most significant of which are carbon emissions, which account for most environmental pollutants (Figure 2).

\section{Results}

Emissions must be monitored to ensure that the $\mathrm{CO}_{2}$ capture system at the facility is operating properly. Gasmet creates FTIRbased gas analyzers and emission monitoring systems for measuring gaseous emissions from industrial operations. The polymer was examined at the Ministry of Defense's Chemical Warfare Department facilities in Egypt, and it was found to absorb 53 percent of the carbon dioxide that went through it as depicted in Figure 3.

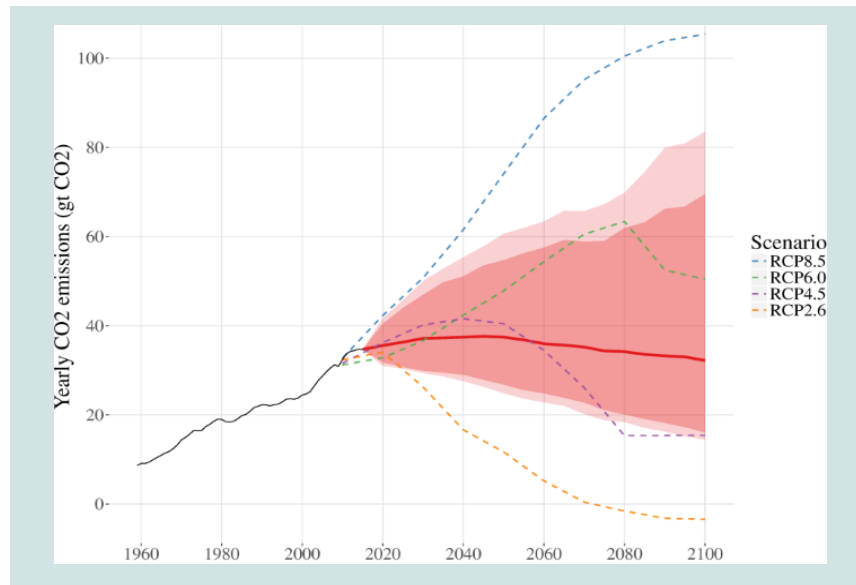

Figure 1: Updated probabilistic forecast of $\mathrm{CO} 2$ Emissions, based on data to 2015 and the method of Raftery et al (2017) [9].
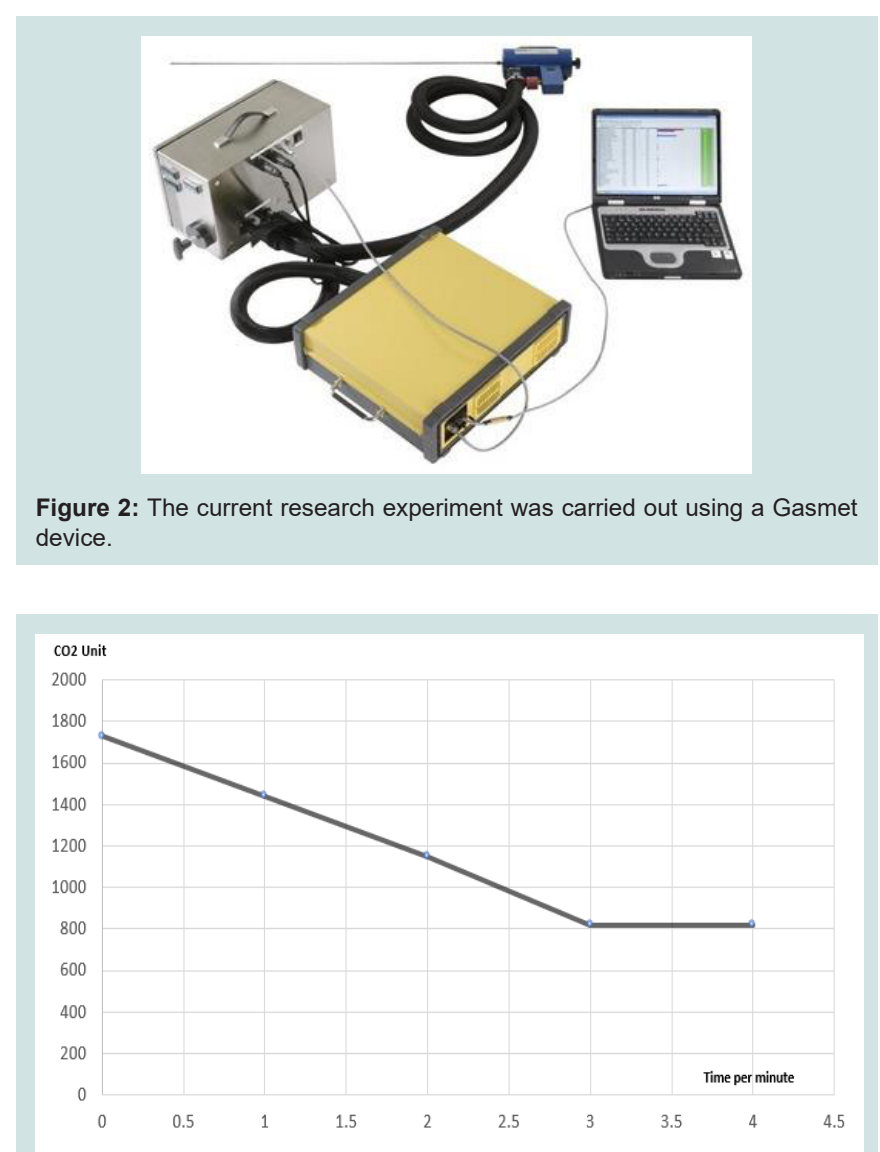

Figure 3: Carbon absorption experience through polymer technology

\section{Discussion}

The gradual warming of the Earth's temperature caused by human activity is mostly driven by greenhouse gases, which are so named because they allow sunlight to enter the atmosphere while preventing heat from exiting, much like the glass of a greenhouse. Because carbon dioxide is the greenhouse gas generated in the highest quantity by human activity, a race is on to limit the amount of it reaching the atmosphere, with significant resources being invested in 
Citation: Hesham Mohamed Yehia AS, Mahmoud Said S. The Potential Applications of a Silica Polymer to Absorb Carbon Dioxide. J Environ Stud. 2021;7(1): 3 .

\section{ISSN: 2471-4879}

studies to minimize fossil fuel consumption. It is clear from the results of the research that there is a noticeable decrease in the percentage of carbon in the air that reached $53 \%$, as carbon rates were tested before with a measurement of 1730 unit, and after the experiment the result was 820 unit, and this is an important step towards addressing the forms of pollution resulting from fossil and industrial carbon.

In fact, one of the disadvantages of using fossil energy is the combustion of fossil fuels, which is one of the main factors of air pollution and causing global warming, which in turn results from gases that envelop the atmosphere and prevent heat reflection from the Earth from transferring it to the outside of the planet, which causes an increase in Earth temperatures, and increases desertification and drought [10]. This finding is consistent with that of 11. Jargin (2021) who confirmed that human activity harmful to the environment can be determined by modifying the behavior of individuals, using alternative energy materials such as wind energy, solar energy, and reducing as much as possible the rates of burning carbon dioxide [11].

Based on the results shown in the following research, many different applications can be obtained that help absorb carbon dioxide, for example, installing filters and developing existing filters to absorb carbon dioxide inside air conditioners in homes. Filters can also be installed in cars and vehicles with carbon exhaust, including factory chimneys, especially cement factories and refractory bricks, polymer uses can also be developed for the benefit of petroleum companies in a way that maintains a green environment and all our operations become carbon neutral in order to reach our nominal goal zero emissions.

\section{Conclusion}

One of the most difficult challenges in post-combustion capture is separating the relatively tiny percentage of $\mathrm{CO}_{2}$ from the huge amounts of nitrogen in the flue gas. Furthermore, implementing carbon capture to different types of flue gas streams comes with its own set of challenges. In this study we developed a polymer of silica that could absorb carbon dioxide. Gasmet creates FTIR-based gas analyzers and emission monitoring systems for measuring gaseous emissions from industrial operations was used in this experiment. The results showed a 53 percent reduction in carbon dioxide levels, which is a groundbreaking step toward reaching zero emissions.

\section{References}

1. Jahanger A, Usman M, Balsalobre-Lorente D (2021). Autocracy, democracy, globalization, and environmental pollution in developing world: fresh evidence from STIRPAT model. Journal of Public Affairs 2753.

2. Oztig LI(2017). Europe's climate change policies: The Paris Agreement and beyond. Energy Sources, Part B: Economics, Planning, and Policy 12: $917-$ 924.

3. Shindell D, Faluvegi, G, Seltzer K, Shindell C (2018). Quantified, localized health benefits of accelerated carbon dioxide emissions reductions. Nat Clim Chang 8: 291-295

4. Narancic T, Verstichel S, Reddy Chaganti S, Morales-Gamez L, Kenny S $T(2018)$. Biodegradable plastic blends create new possibilities for end-oflife management of plastics, but they are not a panacea for plastic pollution. Environ Sci Technol 52: 10441-10452.

5. Howarth RW (2015). Methane emissions and climatic warming risk from hydraulic fracturing and shale gas development: implications for policy. Energy and Emission Control Technologies 3: 45-54.

6. Wang Q, Chen X, Jha AN, Rogers H (2014) Natural gas from shale formationthe evolution, evidence and challenges of shale gas revolution in United States. Renewable and Sustainable Energy Reviews 30: 1-28.

7. Goeppert A, Czaun M, Jones JP, Prakash GS, Olah GA (2014). Recycling of carbon dioxide to methanol and derived products-closing the loop. Chemical Society Reviews 43: 7995-8048.

8. Saunois M, Stavert AR, Poulter B, Bousquet P, Canadell JG (2020). The global methane budget 2000-2017. Earth System Science Data 12: 15611623.

9. Raftery AE, Zimmer A, Frierson DM, Startz R, Liu P(2017). Less than 2 C warming by 2100 unlikely. Nat Clim Chang 7: 637-641.

10. Chen J, Gao M, Li D, Song M (2020). Analysis of the rebound effects of fossil and nonfossil energy in China based on sustainable development. Sustainable Development 28: 235-246.

11. Jargin SV (2021) Environmental damage and overpopulation: Demographic aspects. J Environ Stud 7: 4. 